\title{
Relación entre zooplancton y bacterias en un lago eutrófico (Mèndota, Wisconsin, EE.UU.)
}

\author{
Carlos Pedrós-Alió
}

Departament of Bacteriology University of Wisconsin/Madison Madison, Wisconsin, EE.UU.

Dirección actual: Departamenteo de Microbiología Facultad de Ciencias

Universidad Autónoma de Barcelona Bellaterra, Barcelona, España

\begin{abstract}
SUMMARY
THE ZOOPLANKTON-BACTERIA INTERACTION IN AN EUTROPHIC LAKE (MENDOTA, WISCONSIN, EEUU)
\end{abstract}

Zooplankters eat bacteria in natural systems, but the impact of this mechanism on removing the biomass of the bacterioplankton of freshwaters is unknown. Zooplankton abundance and biomass were followed during two years in Lake Mendota, as well as bacterial biomass and heterotrophic production. Feeding of zooplankton on bacteria was measured by a cell counts method in 1979 and with radioactively labelled natural assemblages of bacteria in 1980 . Total feeding removed range between $1 \%$ and $60 \%$ of the bacterial biomass daily. Annually, it accounted for between $1 \%$ and $10 \%$ of the bacterial heterotrophic production. Since bacterial biomass does not change significantly from year to year and yet bacterial production is very high compared to feeding by zooplankton, mechanims other than feeding must exist. which remove biomass from the epilimnetic bacteria in larger amounts.

\section{INTRODUCCION}

El propósito del presente trabajo fue elucidar la importancia que la alimentación por el zooplancton pudiera tener sobre las bacterias. Este problema surgió de un estudio más general de la dinámica del bacterioplancton en el lago Mendota (PEDROS-ALIO, 1981). Durante dos años se midieron la biomasa y producción bacterianas, pero mientras que la biomasa fue relativamente constante la mayor parte del año, la producción fue sumamente elevada, principalmente de junio a octubre. Por lo tanto, se hacía necesaria la existencia de uno o varios mecanismos que eliminaran biomasa bacteriana del lago para contrarrestar la elevada producción.

Uno de los mecanismos que se han propuesto muchas veces es la alimentación por el zooplancton (NAUWERCK, 1963; SOROKIN \& PAVELJEVA, 1972). Es conocido que varias especies de zooplancton ingieren bacterias en el laboratorio (PETERSON et. al., 1978; STARKWEATHER et. al, 1979) e incluso pueden llegar a reproducirse con una dieta exclusivamente bacteriana (MANUILOVA, 1958; RIEPER, 


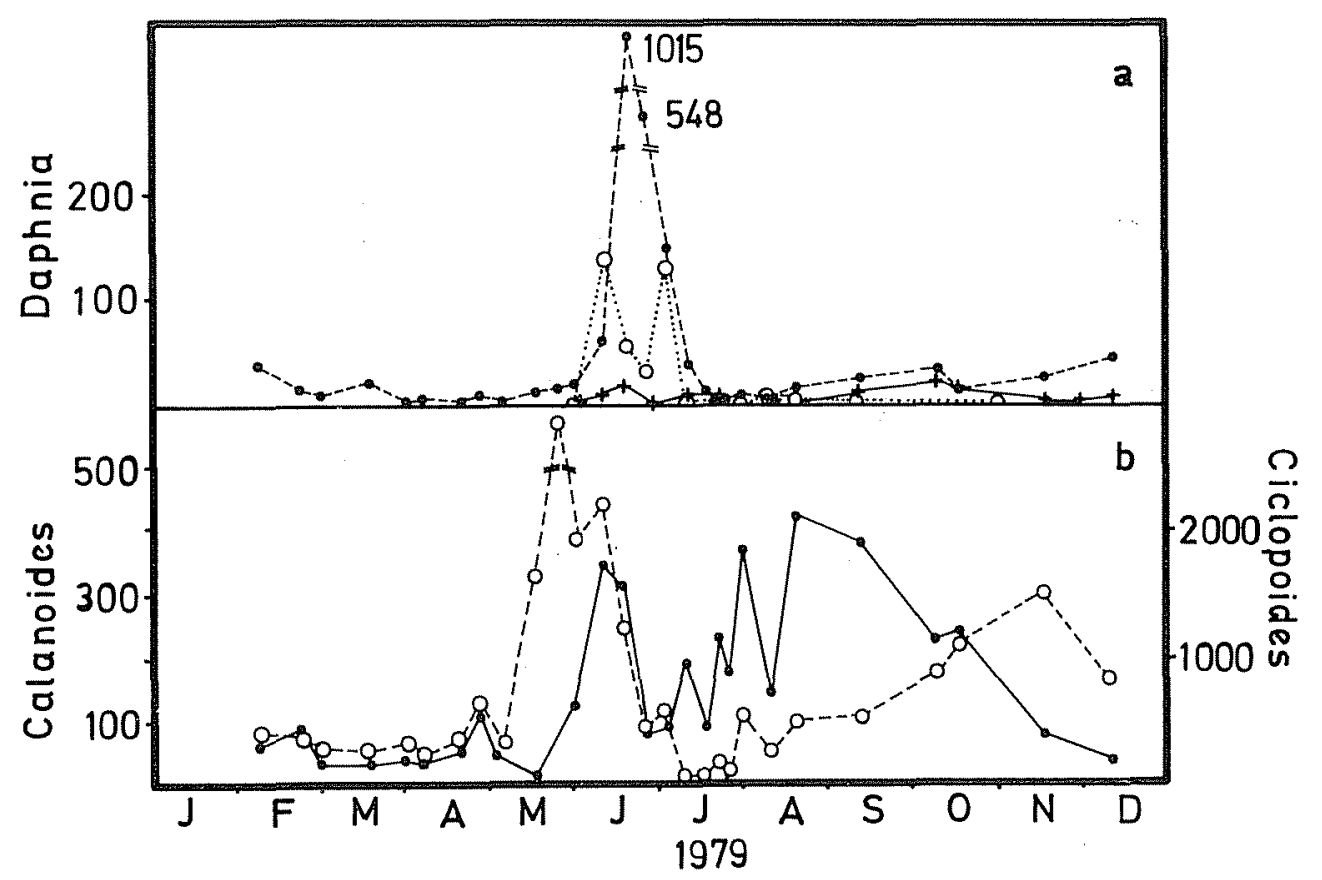

Fig. 1. Abundancia (en individuos $\times 10^{-3} / \mathrm{m}^{2}$ ) del zooplancton en 1979. a) Especies de Daphnia: D. galeata mendotae (puntos negros, línea discontínua), $D$. retrocurva (cruces, línea contínua) y $D$. parvula (círculos, línea punteada). b) Copépodos clanoides (puntos negros) y copépodos ciclopoides (círculos blan$\cos )$.

1978). Es más, se ha comprobado que el zooplancton ingiere bacterias en su medio natural (GLIWICZ, 1969; HANEY, 1973), pero la. importancia de este proceso en la naturaleza no se ha medido nunca de manera directa y cuantitativa.

El lago Mendota ofrecía la posibilidad de estudiar este problema en un lago eutrófico, donde las bacterias parecen tener mayor importancia en la dieta del zooplancton (GLIWICZ, 1969) y tienen mayor tamaño (PEDROS-ALIO \& BROCK, 1982.) lo que las hace más apropiadas como alimento para el zooplancton. Además, se disponia de un cúmulo de datos fisicoquímicos y biológicos procedentes de estudios simultáneos sobre otros aspectos del lago.

\section{MATERIAL Y METODOS}

El Lago Mendota se halla en la cuenca del rio Yahara, en el estado de Wisconsin
(EEUU), tiene $39 \mathrm{Ha}$ de superficie y $24 \mathrm{~m}$. de profundidad máxima. El lago es eutrófico debido a los aportes de fertilizantes empleados en los campos de cultivo que se hallan en su cubeta de recepción. Las muestras se tomaron por duplicado con botellas Van Dorn de 5 litros y con mangas planctónicas. Los animales se contaron bajo una lupa binocular y se midió la longitud de al menos 30 individuos de cada especie para cada muestra. Los coeficientes de variación entre las réplicas de las muestras se hallaron entre el 15 y el $42 \%$. La biomasa se calculó mediante las rectas de regresión de peso seco en función de la longitud publicadas por DUMONT et. al., (1975) y una relación carbono/peso seco de 0,40 .

Los experimentos de alimentación se llevaron a cabo marcando una población natural de bacterias con acetato $-14 \mathrm{C}$ e incubando muestras de zooplancton en agua del lago con 1 a $2 \mathrm{ml}$. de dicha suspensión bacteriana lavada para excluir el ${ }^{14} \mathrm{C}$ disuel- 
to. La radiactividad de esta suspensión se determinó añadiendo $0,2 \mathrm{ml}$. de la misma a $10 \mathrm{ml}$. de Aquasol y analizándola en un contador de centelleo. Las incubaciones se efectuaron en botellas de vidrio de $250 \mathrm{ml}$. con tapón de rosca, en los que se introducía el zooplancton natural correspondiente a $500 \mathrm{ml}$. de agua del lago. Tras 15 a $20 \mathrm{~min}$ de incubación se mataban los animales con formaldehido, se separaban los individuos de cada especie y se colocaban de 10 a 30 en viales de centelleo distintos para cada especie

$$
\text { Tasa de filtración }=\frac{1-C}{\begin{array}{l}
\text { dpm añadidas } \\
\text { por } m l
\end{array}} \times \frac{1440 \mathrm{~min} / \text { día }}{\begin{array}{c}
\text { tiempo incu- } \\
\text { bación (min) }
\end{array}}
$$

donde I son las dpm incorporadas por individuo en el experimento y $\mathrm{C}$ las dpm incorporadas por individuo en el control. A partir de las tasas de filtración para cada especie y para cada día de muestreo y de las abundancias de bacterias y de zooplancton se pudo calcular la alimentación total. La biomasa de las bacterias se calculó a partir de enumeracirin's totales con microscopia de epifluorescencia (HOBBIE et. al., 1977) y de los volúmenes medios para cada día de muestreo obtenidos en fotografías con el microscopio electrónico de barrido en las que se median las dimensiones de al menos 300 bacterias.

La producción bacteriana se midió con la técnica de la incorporación en la oscuridad de sulfato-35S (CAMPBELL \& BAKER, 1978) y suponiendo una relación carbono/ azufre de 50/1. La biomasa del fitoplancton se midió con la técnica de FALLON \& BROCK (1980).

\section{RESULTADOS}

En la figura 1 se muestran las abundancias de los distintos grupos taxonómicos presentes en el lago durante 1979. El ciclo anual fue muy similar durante 1980. La figura 2 muestra la biomasa del zooplancton para 1979 y 1980, así como las contribuciones de cada grupo taxonómico a la biomasa total a lo largo del año. La tabla I resume las tasas d? alimentación del zooplancton sobre con unas gotas de hipoclorito sódico para disolver los caparazones y $10 \mathrm{ml}$. de Aquasol. Se realizaron dos tipos de control: con animales muertos y bacterias marcadas y con animales vivos y bacterias sin marcar. Se hicieron todas las medidas por triplicado. La radiactividad de todas estas preparaciones se determinó con un contador de centelleo. La eficiencia se determinó por el método de las razones entre canales. La tasa de filtración en $\mathrm{ml} /$ individuo/día se podía calcular mediante la fórmula:

bacterias para los dos años del estudio. La figura 3 resume los resultados de la alimentación para 1979. Los resultados de 1980 fueron muy similares. Se han añadido las biomasas del fitoplancton y de las bacterias

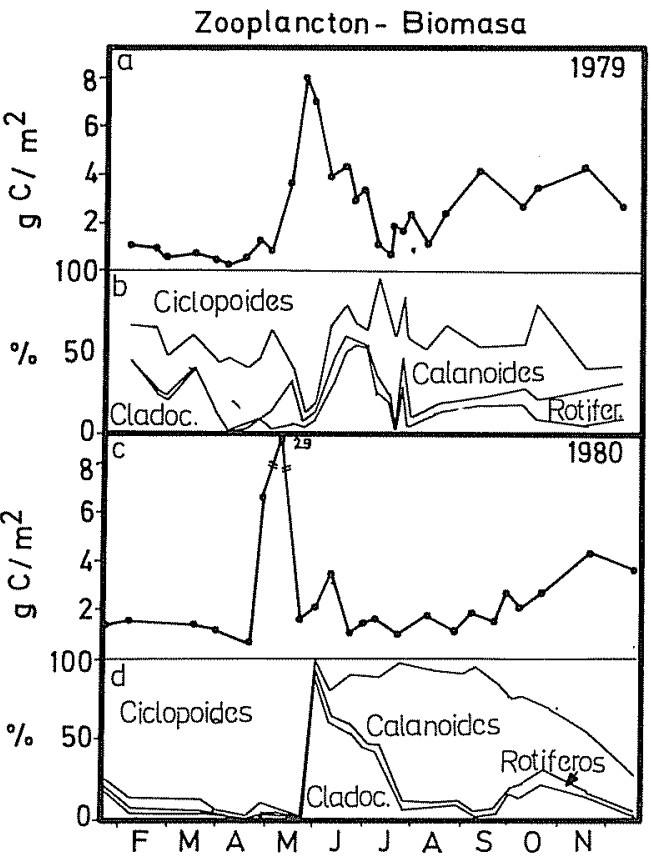

Fig. 2. Biomasa del zooplancton durante 1979 y 1980 . a) Peso de carbono para 1979 . b) Porcentaje de la biomasa en distintos grupos taxonómicos. c) Peso en carbono para 1980. d) Igual que b) para 1980. 
Especie

1979

Daphnia gaieata mendotae

Copépodos ciclópidos (adultos + copepoditos)

Copépodos calanoides (adultos + copepoditos)

1980

Dapinia galeata mendotae

D. retrocurva \& $D$. parvula

Diaphanosoma leuchtenbergianum

Chydorus sphaericus

Bosmina Iongirostris

Copépodos ciclópidos (adultos +

copepoditos)

Nauplios de copépodos

Copépodos calanoides adultos

Rotíferos

para su comparación con la alimentación. En la tabla II se comparan la producción bacteriana y la consumición de bacterias por el zooplancton.

\section{DISCUSION}

Las poblaciones del zooplancton siguen, en el Lago Mendota, un ciclo llamativamente constante a través de los años. Los datos disponibles desde 1976 (PEDROS-ALIO, WOOLSLY \& BROCK, 1983), junto a las observaciones de BIRGE (1897) en 1895 y 1896, indican que la misma sucesión de grupos se ha venido produciendo cíclicamente desde hace casi 100 años.

Durante el invierno el lago posee una capa de hielo de 40 a $60 \mathrm{~cm}$. de espesor, la temperatura es de 1 a $2^{\circ} \mathrm{C}$ y las poblaciones de zooplancton son bajas, principalmente constituidas por Diacyclops bicuspidatus thomasii, algunas Daphnia galeata mendotae

$\begin{array}{ccc}\text { Masa de } & \begin{array}{r}\text { filtración } \\ \text { I.C. } 95 \%\end{array} & \begin{array}{r}\text { Número de } \\ \text { experimentos }\end{array} \\ 2,602 & 1,986 & 5 \\ 1,085 & 1,006 & 4 \\ & & \\ 3,820 & 4,526 & 4 \\ & & \\ 1,626 & 0,925 & 8 \\ 0,300 & - & 1 \\ 0,393 & 0,319 & 5 \\ 0,245 & 0,342 & 12 \\ 0,365 & 0,064 & 2 \\ & & \\ 0,112 & 0,088 & 21 \\ 0,045 & 0,029 & 20 \\ 1,023 & 0,387 & 21 \\ 0,321 & 0,370 & 6 \\ 0,012 & 0,011 & 10 \\ 0,021 & 0,016 & 6\end{array}$

adultas y unos pocos copépodos calanoides (fig. 1). Perfiles verticales no mostrados en el presente trabajo (PEDROS-ALIO, WOOLSLY \& BROCK, 1983) indican una acumulación de $D$. $b$. thomasii hacia el fondo del lago donde experimentan diapausa invernal en estadio de copepodito IV, con muy baja actividad metabólica e, incluso, en un entorno anaerobio.

Al fundirse el hielo en abril y aumentar la temperatura, los copepoditos de $D$. b. thomasii alcanzan la madurez y ocasionan un máximo de abundancia en mayo (figs. 1 y 2). Seguidamente hay un brusco aumento de D. g. mendotae en junio que con sus actividades filtradoras contribuye a eliminar el alimento disponible: clorofíceas, diatomeas y bacterias (fig. 3a). Al desaparecer estas algas el epilimnion del lago queda disponible para su colonización por cianofíceas, que el zooplancton no puede filtrar (FALLON \& BROCK, 1980). Por ello desaparece el máximo de Daphnia y aparecen concentra- 
ciones moderadas de copépodos calanoides y de los cladóceros Diaphanosoma leuchtenbergianum y Chydorus sphaericus. Por fin, a lo largo del otoño, se vuelve lentamente a las condiciones invernales.

Las tasas de alimentación más elevadas corresponden al cladócero D. g. mendotae y a los copépodos calanoides (tabla I) y, por lo tanto, el mayor impacto sobre las bacterias se produce, precisamente, cuando D.g. mendotae alcanza su máximo de abundancia (fig. 3). Aunque los calanoides también tienen una tasa de alimentación elevada su abundancia no es nunca lo suficientemente alta para que el impacto global sea muy grande. Como se puede apreciar en la fig. 3, la alimentación por el zooplancton puede eliminar hasta un $60 \%$ de la biomasa bacteriana cada día durante el máximo de $D$. g. mendotae, entre el 10 y el $20 \%$ durante el verano, principalmente debido a las actividades de los copépodos calanoides, y apenas un $5 \%$ durante el invierno, ya que la mayor parte de la población se compone de ciclopoides con muy bajas tasas de alimentación. Estas cifras son sustanciales (equivalentes a $15-20 \mathrm{mg}$. $\mathrm{C} / \mathrm{m}^{2} /$ día) en términos de biomasa, pero cuando se considera que la producción bacteriana es del orden de $300-500 \mathrm{mg}$. C/m² $/$ dia (tabla II) se comprende que el impacto sobre la población bacteriana es muy limitado. En esta tabla se resumen los valores medio diario, extremos diarios y total anual de la producción

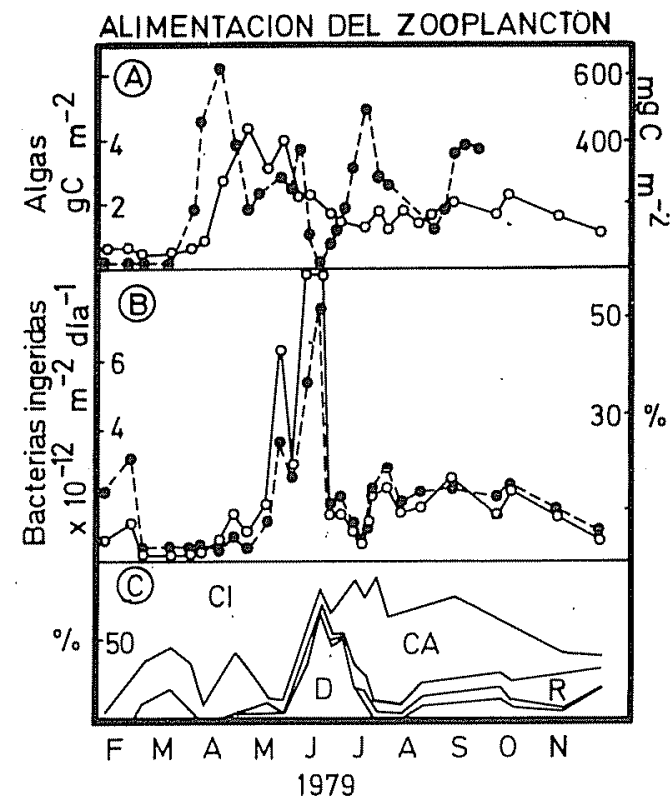

Fig. 3. Alimentación del zooplancton sobre las bacterias y biomasa del fitoplancton y bacterioplancton en 1979). A) Biomasa del fitoplancton (puntos negros) y del bacterioplancton epilimnético (circulos blancos. B) Alimentación total expresada como bacterias epilimnéticas ingeridas por $\mathrm{m}^{2}$ y por día (círculos blancos) y como porcentaje de las bacterias epilimnéticas ingeridas por día (puntos negros. C) Porcentajes de la alimentación total correspondientes a cada grupo taxonómico: CI, copépodos ciclopoides; CA, copépodos calanoides; $\mathrm{R}$, rotíferos; $\mathrm{D}$, especies del género Daphnia.

TABLA II. Producción bacteriana anual y alimentación sobre las bacterias en 1979 y 1980 .

\begin{tabular}{|c|c|c|}
\hline & 1979 & 1980 \\
\hline \multicolumn{3}{|l|}{ Producción bacteriana } \\
\hline Media dieria $\left(\mathrm{mgC} / \mathrm{m}^{2} / \mathrm{dia}\right)$ & 553 & 561 \\
\hline Variación diaria (mgC/m²/dia) & $285-1430$ & $62-2562$ \\
\hline Total anual $\left(\mathrm{gc} / \mathrm{m}^{2}\right)$ & 202 & 205 \\
\hline \multicolumn{3}{|l|}{ Consumo del zooplancton } \\
\hline Media diaria $\left(\mathrm{mgC} / \mathrm{m}^{2} / \mathrm{dia}\right)$ & 27,3 & 9,0 \\
\hline Variación anual (mgC/m²/dia) & $1,2-136,5$ & $1,0-22,0$ \\
\hline Total anual $\left(\mathrm{gC} / \mathrm{m}^{2}\right)$ & 10,0 & 3,0 \\
\hline \multirow[t]{2}{*}{ Porcentaje de producción. } & 4,9 & 1,5 \\
\hline & 9,3 & 2,6 \\
\hline
\end{tabular}


bacteriana y de la alimentación por el zooplancton. Como puede apreciarse, el zooplancton elimina entre el 1 y el $10 \%$ de la producción bacteriana anualmente. En consecuencia, aunque la alimentación por el zooplancton puede revestir importancia en determinadas épocas del año (en junio por ejemplo) su impacto global es muy limitado, del orden del 1 al $10 \%$ de la producción bacteriana, y no es capaz de explicar la divergencia entre la biomasa constante de bacterias y la alta producción de las mismas que se observan durante la mayor parte del año.

\section{BIBLIOGRAFIA}

BIRGE, E.A. 1897. Plankton studies on lake Mendota. II. The Crustacea of the plankton, July 1894-December 1896. Trans. Wisc. Acad. Sci. Arts. Lett., 11: 274-448.

CAMPBELL, P.G.C. \& BAKER, J.H. 1978. Estimation of bacterial production in freshwa ters by the simultaneous measurement of $\left({ }^{35} \mathrm{~S}\right)$ -sulfate and $\mathrm{D}-\left({ }^{3} \mathrm{H}\right)$-glucose uptake in the dark. Cant. J. Microbiol., 24: 939-946.

DUMONT, H.J.; VAN DE VELDE, I. \& DUMONT, S. 1975 . The dry weight estimate of biomass in a selection of Cladocera, Copepoda, and Rotifera from the plankton, periphyton and benthos of continental waters. Oecologia, 19: 75-97.

FALLON, R.D \& \& BROCK, T D. 1980. Planktonic blue-green algae: Production, sedimentation, and decomposition in Lake Mendota, Wisconsin. Limnol. Oceanogr., 15: 72-88.

FENCHEL, T. 1975. The quantitative importance of the benthic microfauna in an arctic tundra pond. Hydrobiologia, 46: 445-464.

GLIWICZ, Z.M. 1969. Studies on the feeding of pelagic zooplankton in lakes with varying trophy. Ekol. Polska, Ser. A, 17: 663-707.

HANEY, J.F. 1973. An in situ examination of the grazing activities of natural zooplankton communities. Arch. Hydrobiol., 72: 87-132.

HOBBIE, J.E.; DALEY, R.J.; \& JASPER, S. 1977. Use of Nuclepore filters for counting bacteria by fluorescence microacopy. Appl. Environ. Microbiol., 33: 1.225-1.228.

MANUILOVA, E.F. 1958. The question of the role of bacterial numbers in the development of cla- docera in natural condition. Biol. Sci. Sect., Doklady, 120: 438-441

NAUWERCK, A. 1963. Die Beziehungen zwischen Zooplankton und Phy toplankton im See Erken. Symbol. Bot. Upsal., 17: 163 págs.

PEDROS-ALIO, C. 1981. Ecology of heterotrophic bacteria in the epilimnion of eutrophic Lake Mendota, Wisconsin. Ph. D. Thesis, University of Wisconsin, Madison.

PEDROS-ALIÓ, C.; \& BROCK, T.D. 1982. Assesing the biomass and production of bacteria in eutro phic Lake Mendota, Wisconsin. Appl. Environ. Microbiol, 44: 203-218.

PEDRÓS-ALIÓ,C.; WOOLSLY, E.\& BROCK, T.D 1983. Plankton studies on Lake Mendota: Secular vs. annual changes in the dynamics of the macrozooplank ton. Trans. Wisconsin. Acad. Sci. Arts Lett., (en prensa).

PETERSON, B.J.; HOBBIE, J.E.; \& HANEY, J.F. 1978. Daphnia grazing on natural bacteria. Limnol. Oceanogr., 23: 1.039-1.044.

RIEPER, M. 1978. Bacteria as food for marine harpacticoid copepods. Mar. Biol., 45: 337-345.

SOROKIN, Y.I.; \& PAVLLJEVA, E.B. 1972. On the quantitative characteristics of the pelagic ecosystem of Dalnee Lake (Kamchatka). Hydrobiologia, 40: 519-552.

STARKWEATHER， P.L.; GILBERT， J.J.; \& FROST, T.M. 1979. Bacterial feeding by the rotifer Brachionus calyciflorus: Clearance and ingestion rates, behavior, and population dynamics. Oecologia, 44: 26-30. 